\title{
UTICAJ PATOGENE GLJIVE SPHAEROPSIS SAPINEA NA IZUMIRANJE ČETINARSKIH VRSTA U SRBIJI I CRNOJ GORI*
}

\section{The effect of Sphaeropsis sapinea on conifer decline in Serbia and Montenegro}

\author{
Tanja Milijašević ${ }^{1}$
}

\begin{abstract}
Sphaeropsis sapinea is widely distributed in Serbia and Montenegro. It is recorded on Pinus nigra, $P$. sylvestris, $P$. halepensis, $P$. jeffrey, $P$. peuce, $P$. pinaster, $P$. ponderosa, P. pinea, P. mugo, P. heldreichii, Abies concolor, Cedrus atlantica, Chamaecyparis lawsoniana, Cupressus sempervirens, Juniperus virginiana and Thuja occidentalis. Most of the damages occured in Austrian and Allepo pine plantations and also in urban areas. Pinus heldreichii, a Tertiary relic and Balkan subendemit is a new plant host in these countries. The most common symptoms are shoot blight, bud wilt, stem cankers, branch dieback, necroses of the seed cones and their dwarfisness. The critical period of infection is from the middle of April till the middle of May. It infects buds before they are opened in the spring and also in the summer, in the year of their forming, young shoots through the bark and young needles. Changing of color of the infected needles can be seen at the begining of June, while in the middle of June they become yellow-brown. Pycnidia of $S$.sapinea are observed on young shoots and needles, pollen and seed cones, buds, current year and second year seed cones, and in the bark of older branches.
\end{abstract}

Key words: Sphaeropsis sapinea, Pinus decline, Serbia, Montenegro

\section{Izvod}

Sphaeropsis sapinea je široko rasprostranjena parazitna gljiva u Srbiji i Crnoj Gori. Konstatovana je na Pinus nigra, $P$. sylvestris, $P$. halepensis, $P$. jeffrey, $P$. peuce, $P$. pinaster, $P$. ponderosa, P. peuce, $P$. pinea, P. mugo, $P$. heldreichii, Abies concolor, Cedrus atlantica, Chamaecyparis lawsoniana, Cupressus sempervirens, Juniperus virginiana i Thuja occidentalis. Najveće štete uzrokuje u kulturama i urbanim sredinama na crnom i alepskom boru. Pinus heldreichii, tercijerni relikt i balkanski subendemit je nov domaćin u ovim zemljama. Najčešći simptomi su izumiranje

\footnotetext{
* Rad prezentiran na međunarodnoj naučnoj Konferenciji "Šumarska nauka između ekonomije i zahtjeva društva", povodom 60. godišnjice Šumarskog fakulta Univerziteta u Sarajevu, Sarajevo, hotel "Hollywood" 8 - 10.10.2008. godine

${ }^{1}$ Šumarski fakultet Univerziteta u Beogradu, Srbija - University of Belgrade, Faculty of Forestry, Serbia
} 
pupoljaka, izbojaka i četina iz tekuće vegetacije, grana sa vrha, nekroza i zakržljalost šišarica. Kritičan period za infekcije je od sredine aprila do sredine maja. Može da ostvari infekciju preko pupoljaka u proleće, pre njihovog otvaranja i u leto u vreme njihovog formiranja, kroz koru mladih izbojaka i preko četina. Promena boje inficiranih četina uočljiva je početkom juna, da bi sredinom ovog meseca one postale žutosmeđe. Piknidi gljive konstatovani su na ovogodišnjim izbojcima i četinama, pupoljcima, muškim i ženskim cvetovima, jednogodišnjim i dvogodišnjim šišaricama i u kori starijih grana.

Ključne reči: Sphaeropsis sapinea, Pinus vrste, Srbija, Crna Gora

\section{UVOD - Introduction}

Sphaeropsis sapinea je parazitna gljiva sa velikim geografskim rasprostranjenjem i velikim brojem domaćina. Konstatovana je u preko 50 zemalja sveta, na 11 četinarskih rodova, ali su najugroženije i najčešće biljke domaćini Pinus vrste. Štete koje izaziva na borovima konstatovane su u celom svetu i imaju za posledicu smanjenje proizvodnje i kvaliteta drveta. Prema brojnim literaturnim izvorima, najosetljivije vrste borova su $P$. radiata, $P$. nigra, $P$. sylvestris, $P$. ponderosa, P. resinosa, P. mugo, P. pinaster i P. elliottii (ButIn, 1989; Chou, 1976a,b; 1977; 1978; 1981; 1982a; De KAM, 1985; 1991; GeRHOLD, I SAR. 1994; NICHOLLS I OSTRY, 1990; PIOU I SAR., 1991; SWART I WINGFIELD, 1991a; SWART I SAR., 1988; ZHONG I LIANG, 1990).

U Srbiji i Crnoj Gori je ovaj patogen široko rasprostranjen i u kontinentalnom i u mediteranskom delu. Prvi put je konstatovan 1981.god. na P.nigra u rasadniku Devojački bunar na Deliblatskoj peščari (KARADžıć, 1983) i od tada u kulturama crnog $\mathrm{i}$ belog bora $\mathrm{u}$ ovom prirodnom rezervatu predstavlja permanentan problem. Epifitocije prouzrokovane ovom gljivom, konstatovane su i na Subotičko-Horgoškoj peščari i na mnogim drugim lokalitetima. U Crnoj Gori se S. sapinea javlja na primorskim vrstama borova - P.halepensis, P.pinaster i P.pinea. Posebno velike štete izaziva u kulturama crnog bora na Lovćenu, kao i u kulturama alepskog bora na celoj Jadranskoj obali. U urbanim sredinama predstavlja jednu od najčešćih i najopasnijih parazitnih gljiva. Istraživanja nekih autora pokazala su da određeni polutanti deluju stimulativno na njen razvoj.

Značaj $S$. sapinea je u tome što ima široko rasprostranjenje i veliki spektar domaćina. Jedna je od retkih gljiva koja može da parazitira gotovo sve biljne organe $\mathrm{i}$ da na njima izaziva brojne simptome.

Cilj ovog rada je da ukaže na značaj koji gljiva $S$. sapinea ima u Srbiji i Crnoj Gori, da prikaže njen životni ciklus, morfološke i neke fiziološke karakteristike, patogenost i mogućnosti suzbijanja. 


\section{MATERIJAL I METOD - Material and methods}

Istraživanje životnog ciklusa gljive vršeno je pet godina, najvećim delom u prirodno inficiranim kulturama crnog i belog bora na Deliblatskoj peščari, ali i na drugim lokalitetima u Srbiji i Crnoj Gori.

Ispitivanje mogućnosti ostvarivanja infekcije preko pupoljaka vršeno je izolacijom iz pupoljaka i identifikacijom piknida gljive na njima. Između $10-20$ pupoljaka uzimano je sa potpuno zdravih izbojaka crnog bora u letnjem periodu - VI IX (izolacija iz pupoljaka formiranih u tekućoj godini) i zimskom - I-IV (izolacija iz pupoljaka formiranih prethodne godine). U ovaj period uključen je i decembar da bi se utvrdilo da li gljiva može prezimiti u pupoljcima.

Kritičan period za infekciju izbojaka i četina ispitan je u okviru terenskih istraživanja, prvenstveno na Deliblatskoj peščari. Istraživanja su obuhvatila i veštačke infekcije petogodišnjih sadnica crnog bora u arboretumu Šumarskog fakulteta u Beogradu, pri čemu je istražena i patogenost gljive. Inokulacije su u periodu 25.4. 3.8. vršene u intervalima od deset dana, a kao izvor inokuluma poslužile su četine i ljuspice šišarica $P$. nigra sa zrelim piknidima gljive. Sadnice su zatim pokrivene perforiranim polivinilskim kesama. Broj inficiranih biljaka u svakoj seriji ogleda iznosio je između 13 i 26, a broj inokulisanih izbojaka između 40 i 80 . Svakih deset dana donošene su zaražene četine i šišarice za inokulaciju novih sadnica. Sa biljaka iz prethodne serije uklanjane su kese i zaražene četine i šišarice. Analiza inficiranih sadnica vršena je svakih deset dana, a intenzitet infekcije određen je na osnovu procenta nekrotiranih izbojaka od ukupnog broja izbojaka na sadnicama.

Istraživanje mogućnosti infekcije muških i ženskih cvetova vršeno je izolacijom iz cvetova crnog bora i identifikacijom piknida gljive na njima.

Ispitivanje vremena kada dolazi do infekcije šišarica rađeno je tako što su šišarice crnog bora sakupljane jednom mesečno sa prirodno inficiranih stabala $u$ kulturama na Delibatskoj peščari. Na najmanje 10 šišarica u prvoj i drugoj godini razvoja analizirano je prisustvo piknida, pre i posle stavljanja u uslove koji stimulišu razvoj fruktifikacija. Šišarice su, naime, posle sterilizacije u 95\% alkoholu i ispiranja sterilisanom destilovanom vodom, stavljane u petri posude na vlažnu filter hartiju, a zatim u termostat na temperaturu od $24{ }^{\circ} \mathrm{C}$. Posle tri nedelje one su analizirane da bi se na njima utvrdilo prisustvo piknida. Osim navedenog, metod za utvrđivanje da li su šišarice inficirane bila je izolacija.

Prilokom ispitivanja morfoloških karakteristika analizom je obuhvaćeno najmanje 100 piknida i 200 konidija.

Patogenost gljive ispitana je veštačkim inokulacijama četvorogodišnjih sadnica crnog bora u polju i u kontrolisanim uslovima sa izolatima iz šest Pinus vrsta, poreklom sa devet lokaliteta. Svakim izolatom inficirano je dvadeset sadnica. Deset sadnica je bilo neoštećeno. Drugih 10 je oštećeno tako što je sa svakog izbojka uklonjeno nekoliko rukavaca četina.Veštačke infekcije vršene su u periodu 20.5. - 10.6. suspenzijom spora iz piknida obrazovanih u kulturi. Suspenzija je nanošena na četine i izbojak medicinskim špricom. Po deset kontrolnih biljaka isprskano je destilovanom vodom. Zatim su sadnice pokrivene polietilenskim kesama i stavljene u klimakomoru, na temperaturu od $21{ }^{\circ} \mathrm{C}$. 
Kese su skinute posle 48 sati, a trećeg dana biljke su prenesene u laboratoriju, gde su pojava i razvoj simptoma praćeni svakodnevno. Iz nekrotiranih izbojaka je nakon mesec dana vršena izolacija. Veštačke infekcije u polju vršene su na petogodišnjim sadnicama crnog bora, na način koji je već opisan.

Uticaj temperature na porast 11 izolata gljive ispitan je na podlogama MEA i PDA spravljenim prema recepturi Bootha-a (1971). Kulture su dobijene izolacijom gljive iz nekrotiranih izbojaka tekuće vegetacije, nakon njihove sterilizacije rastvorom $\mathrm{Na}$ hypohlorita u trajanju od $5 \mathrm{~min}$. Po tri petri posude, za svaki izolat stavljane su u termostate, a inkubacija je trajala 4 dana. Kontrola porasta vršena je svakodnevno, tako što su merena dva unakrsna prečnika kolonije. Porast micelije ispitan je na temperaturama $4^{\circ}$, $10^{\circ}, 15^{\circ}, 20^{\circ}, 25^{\circ}, 28^{\circ}, 35^{\circ}$ i $40^{\circ} \mathrm{C}$. Ogled je ponovljen tri puta.

\section{REZULTATI ISTRAŽIVANJA - Results}

\subsection{Rasprostranjenje i biljke domaćini - Distribution and hosts}

U Srbiji i Crnoj Gori je ova gljiva široko rasprostranjena. Posebno je česta u kulturama na Deliblatskoj i Subotičko-Horgoškoj peščari, gde godinama izaziva epifitocije, posebno kada se javi zajedno sa gljivom Mycosphaerella pini (anamorph Dothistroma septospora). Takođe je konstatovana na Fruškoj Gori, Bukulji, okolini Brusa, Donjeg Milanovca i Tršića, NP "Tara", Debelom Lugu, u parkovima i na drugim kategorijama zelenih površina Beograda, Gornjeg Milanovca, Vrnjačke Banje, Aranđelovca, Loznice, Trstenika, Oplenca, Ražnja, Kraljeva, u NP "Lovćen", NP "Durmitor", okolini Virpazara, Nikšića, u Podgorici, kao i u kulturama i na parkovskim stablima duž Jadranske obale. Posebno jake zaraze konstatovane su na crnom boru, kako u Crnoj Gori (Podgorica, Budva, Miločer), tako i u Srbiji (Beograd, Loznica, Vrnjačka Banja, Kraljevo).

U parkovima Beograda ova gljiva se na P.nigra više od deset godina javlja $u$ gotovo epifitotičnim razmerama. Višegodišnji uzastopni napadi doveli su do propadanja celih biljaka, tako da je na najugroženijim lokalitetima moralo biti uklonjeno više od $30 \%$ stabala. Štete su posebno bile izražene na Novom Beogradu, Zemunu i na Kalemegdanu.

$S$. sapinea je zabeležena na deset vrsta borova i na pet domaćina iz drugih četinarskih rodova - Pinus nigra, $P$. sylvestris, $P$. halepensis, $P$. pinaster, $P$. jeffrey, $P$. ponderosa, P. pinea, P. heldreichii, P. peuce, P. mugo, Abies concolor, Cedrus atlantica, Chamaecyparis lawsoniana, Cupressus sempervirens i Juniperus virginiana. Najosetljivije su Pinus vrste, dok se na vrstama iz drugih navedenih četinarskih rodova gljiva javlja sporadično i ne izaziva veće štete (KARADŽı́c, 1983; KARADŽIĆ I VUJANOVIĆ, 1992; MILIJAŠEVIĆ, 2000).

$P$. peuce i $P$. heldreichii, tercijerni relikti i balkanski endemiti, odnosno subendemiti, predstavljaju nove biljke domaćine gljive na ovim prostorima (KARADžlĆ I MILIJAŠEVIĆ, 1998; MILIJAŠEVIĆ, 1994). Među biljnim vrstama iz drugih rodova, kao domaćin $S$. sapinea prvi put je navedena Abies concolor upravo u Srbiji. Naime, u 
okviru istraživanja bolesti četina A. concolor, konstatovana je na Avali (MILIJAŠEVIĆ, 1987). U našoj zemlji je kao domaćin gljive ova biljna vrsta navedena i 1988.g. (KARADŽIĆ I STOJADINOVIĆ, 1988), iste godine kada je zabeležena u SAD (LULEY I GLEASON, 1988).

U Srbiji i Crnoj Gori je najosetljivija vrsta $P$. nigra, dok je u mediteranskom delu, osim crnog, osetljiv i alepski bor (KARADŽIĆ, 1983; KARADŽIĆ I VUJANOVIĆ, 1992; MILIJAŠEVIĆ, 1994a,b,c; 2000).

\subsection{Morfološke karakteristike gljive - Morphological characteristic}

Plodonosna tela gljive su piknidi koji su u ovim istraživanjima konstatovani na četinama, u kori, na šišaricama, semenu, pupoljcima i muškim i ženskim cvetovima.

Piknidi su najčešće loptasti ili kruškasti, tamnosmeđi do crni, debelih zidova oko ostiole, koja je centralna, kružna ili bradavičasta, ćelije su tamnije obojene. Mogu se obrazovati pojedinačno, u grupi ili ređe u zajedničkoj stromi. Njihova veličina je $138-715$ x $136-729 \mu \mathrm{m}$, sa prosečnim prečnikom $226-350 \mu \mathrm{m}$. Takođe je utvrđeno da veličina fruktifikacija zavisi i od biljke domaćina i od mesta njihovog obrazovanja.

Konidije gljive su u početku bezbojne, a zatim postaju obojene, najpre su žućkaste, zatim žućkastosmeđe i na kraju su smeđe do tamnosmeđe. Citoplazma je granulozna, a njihova membrana je u najvećem broju slučajeva zadebljala. Najčešće su eliptične, mada mogu biti i batinaste, sa zaobljenim vrhom i ravnim bazalnim delom. Uglavnom su jednoćelijske, retko dvoćelijske i još ređe višećelijske (u starim piknidima). Veličina konidija, prema podacima iz literature kreće se u širokom dijapazonu $16,8-55,0 \times 7,0-21,0 \mu \mathrm{m}$. Naša istraživanja pokazala su da je njihova veličina i na ovim prostorima varijabilna i da iznosi $14,8-51,4$ x 9,7-20,2 $\mu \mathrm{m}$, sa prosečnom dužinom $26,1-36,8 \mu \mathrm{m}$ i prosečnom širinom $12,6-15,8 \mu \mathrm{m}$. Utvrđeno je i to da na veličinu konidija utiču vrsta bora i biljni organ na kome se piknidi obrazuju. Naime, najmanje konidije konstatovane su na šišaricama, a najveće u piknidima na pupoljcima i muškim cvetovima. Na primorskim vrstama borova $(P$. halepensis i $P$. pinea) konidije su manje u odnosu na one sa $P$. sylvestris, $P$. nigra i $P$. heldreichii (MILIJAŠEVIĆ, 2000).

\subsection{Simptomi oboljenja i životni ciklus - Symptoms and life cycle}

Glavni simptomi su uvenuće pupoljaka, zakržljalost i nekroza izbojaka i četina iz tekuće ve.getacije, nekroza, deformacija i zakržljalost šišarica.

Prema ovim istraživanjima postoje tri osnovna tipa simptoma:

1. Nekroza celog izbojka - ovakvi izbojci su zakržljali, sa kratkim četinama i njihova dužina zavisi od vremena kada je ostvarena infekcija. Prvi vidljivi znaci infekcije na mladim izbojcima javljaju se u vidu smeđih nekroza, izliva smole i pojave nekoliko kratkih četina na tom mestu. Nekroze se šire brzo, a inficirani izbojci prestaju sa porastom. Zaražene četine počinju da menjaju boju od svoje osnove, početkom juna ili nešto kasnije, sredinom juna masovno postaju žutosmeđe. S 
obzirom da su četine kraće od zdravih i da se lako uočavaju na stablima, ovo je pouzdan znak da je došlo do infekcije. Ponekad se rani simptomi mogu uočiti već i polovinom maja. Na izbojcima se javlja lučenje smole i jedan ili nekoliko rukavaca kratkih četina koje su još uvek zelene.

2. Delimična nekroza zahvata različite delove izbojka i ovaj tip simptoma je ređi od prethodnog. Najčešće ipak dolazi do izumiranja vršnog dela izbojka ili njegove gornje polovine. U oba slučaja gljiva prstenuje izbojak i deo iznad mesta infekcije se suši.

3. Nekroza jednog dela izbojka uslovno je nazvano "tip lokalizovane infekcije". Do infekcije može doći na bilo kom delu izbojka i manifestuje se pojavom jednog ili nekoliko suvih i zakržljalih rukavaca četina. Kod ovog tipa simptoma, ponekad se na mestu infekcije javljaju i jedva primetne hipertrofije, praćene jakim lučenjem smole i prisustvom nekoliko zakržljalih rukavaca četina.

Za razliku od prva dva simptoma, kod kojih je posledica izumiranje izbojaka, kod tipa tzv. "lokalizovane infekcije" u narednom vegetacionom periodu najčešće dolazi do obrazovanja mladih izbojaka.

$S$. sapinea može inficirati i starije grane, usled čega dolazi do njihovog sušenja. Na crnom i alepskom boru zabeležena je i pojava izumiranja vršnih delova stabala. Ovakve pojave su prema našim zapažanjima ipak ređe.

Osim nekroze kore i četina, $S$. sapinea može izazvati i nekrozu šišarica, pri čemu su posebno osetljive šišarice u drugoj godini razvoja na kojima se obrazuju brojni piknidi. Rezultati naših istraživanja pokazali su da su dvogodišnje šišarice crnog bora na infekciju osetljive u periodu od početka druge dekade aprila do kraja maja. Prvi simptomi javljaju se krajem maja u vidu malih, nepravilnih crvenkastosmeđih nekroza koje prati jak izliv smole. One se povećavaju u toku juna i jula, a nekrotirano tkivo dobija tamnosmeđu boju. Do zaraze može doći i na šišaricama u prvoj godini razvoja, što je dokazano izolacijom čiste kulture gljive iz jednogodišnjih šišarica i identifikacijom plodonosnih tela na njima. Izolacijom gljive iz jednogodišnjih šišarica crnog bora sakupljenih u zimskom periodu, utvrđeno je da ona u njima može prezimiti u vidu micelije.

$S$. sapinea takođe izaziva deformaciju i zakržljalost dvogodišnjih šišarica crnog, belog i alepskog bora. Brojne zakržljale šišarice $P$. nigra konstatovane su u prirodno inficiranim kulturama na mnogim lokalitetima u Srbiji i Crnoj Gori. Ovakve šišarice najčešće ostaju zatvorene, a zabeležene su kako na stablima tako i na zemlji. Pojava deformacije i zakržljalosti šišarica u prvoj godini razvoja konstatovana je samo na crnom boru.

Infekcije se ostvaruju preko pupoljaka, kore mladih izbojaka ili kroz stome mladih četina, mada su one moguće i preko ozleda na kori. Do zaraze, ipak, najčešće dolazi preko mladih izbojaka koji su na infekciju najosetljiviji u vremenskom periodu od dve nedelje nakon otvaranja pupoljaka.

Naša istraživanja su pokazala da infekcija preko pupoljaka može izazvati njihovo izumiranje. Ovo je dokazano izolacijom iz pupoljaka, identifikacijom piknida na njima, kao i veštačkim inokulacijama pupoljaka u laboratorijskim uslovima. Takođe je utvrđeno da do infekcije može doći u proleće, pre otvaranja pupoljaka, ali i 
$\mathrm{u}$ leto, odnosno u godini njihovog formiranja. Izolacijom čiste kulture iz pupoljaka crnog bora sakupljenih u zimskim mesecima, kao i konstatacijom piknida na njima, utvrđeno je da gljiva može i prezimiti u pupoljcima.

Piknidi gljive se na izbojcima, četinama i dvogodišnjim šišaricama crnog, belog i alepskog bora mogu obrazovati u toku iste godine kada je ostvarena zaraza. Prve zrele fruktifikacije najčešće se formiraju u kori mladih izbojaka, u zoni infekcije. $\mathrm{Na}$ dvogodišnjim šišaricama retke zrele fruktifikacije obrazuju se početkom treće dekade jula, mada češće krajem avgusta. $U$ istom vegetacionom periodu kada je ostvarena infekcija, konstatovana su plodonosna tela gljive sa zrelim konidijama i na jednogodišnjim šišaricama.

\subsection{Patogenost - Pathogenecity}

Ova vrsta istraživanja prevashodno je imala za cilj da se ispita da li među izolatima gljive postoji razlika u patogenosti, s obzirom da teza nekih autora o postojanju sojeva različite virulencije ima osnova, imajući u vidu njeno široko geografsko rasprostranjenje, veliki broj biljaka domaćina i veliki broj simptoma koje izaziva.

Ispitivanjem patogenosti gljive utvrđeno je da je S. sapinea parazit sposoban da inficira neozleđene mlade izbojke $P$. nigra, što je dokazano veštačkim infekcijama u kontrolisanim uslovima i u polju. Veštačke inokulacije četvorogodišnjih sadnica crnog bora u kontrolisanim uslovima, sa 9 izolata iz 6 različitih Pinus vrsta ( $P$. nigra, $P$. sylvestris, $P$. halepensis, $P$. heldreichii, $P$. pinaster i $P$. pinea) pokazale su da su svi sposobni za infekciju neozleđenih izbojaka. Procenat zaraženih biljaka bio je između $80 \%-100 \%$. Među izolatima ne postoji razlika u patogenosti. Prvi simptomi na izbojcima javili su se posle dva ili tri dana, u vidu kapljice smole i promene boje $u$ tamnozelenu na mestu infekcije. Petog dana konstatovana je i hloroza četina, najčešće u njihovoj osnovi, a desetog dana većina izbojaka bila je suva.

Veštačkim inokulacijama petogodišnjih sadnica $P$. nigra u polju potvrđeno je da gljiva može izazvati sušenje mladih biljaka, ali da tada kolonizira i korenov vrat $\mathrm{i}$ koren, na kojima obrazuje plodonosna tela.

\subsection{Fiziološke karakteristike - Phisiological characteristic}

Konidije klijaju u temperaturnom intervalu između $6^{\circ}$ i $36^{\circ} \mathrm{C}$. Optimalna temperatura za klijanje konidija i za porast inicijalne hife je $27^{\circ} \mathrm{C}$.

Optimalna temperatura za porast micelije na podlogama PDA i MEA je $28^{\circ} \mathrm{C}$, mada je vrlo sličan porast i na $25^{\circ} \mathrm{C}$. Na optimalnoj temperaturi prosečan dnevni porast na PDA iznosi $22 \mathrm{~mm}$, na MEA $18 \mathrm{~mm}$. Na podlozi PDA, osim bržeg porasta, gljiva pokazuje fiziološku aktivnost $\mathrm{u}$ većem temperaturnom intervalu - između $4{ }^{\circ} \mathrm{C} \mathrm{i}$ $40{ }^{\circ} \mathrm{C}$, na MEA - između $10^{\circ} \mathrm{C}$ i $35^{\circ} \mathrm{C}$. Analiza obrazovanja plodonosnih tela u kulturi pokazala je da na sporulaciju utiču svetlost i prisustvo sterilisanih četina na miceliji. Posle 14 dana izlaganja dnevnom svetlu obrazovali su se piknidi, kod većine izolata sa zrelim konidijama, dok su se posle istog perioda inkubacije u mraku, samo kod tri 
izolata obrazovale zrele piknospore. Fruktifikacije gljive se uvek brže i u većem broju formiraju na četinama nego na miceliji.

\subsection{Suzbijanje - Control}

Jedna od osnovnih uzgojnih mera borbe je pravilan izbor staništa i Pinus vrsta. Osetljive borove ne treba saditi u zatvorenim dolinama ili u malim grupama koje su zaklonjene drugim stablima, a ukoliko je to neizbežno, treba intenzivirati proređivanje i prihranjivanje kako bi se ublažio fiziološki stres nastao usled nepovoljnih mikroklimatskih uslova.

U kulturama i u parkovima treba ukloniti sva suhovrha stabla, kao i ona koja imaju više od $80 \%$ suvih izbojaka. Takođe, treba preduzeti mere nege koje će poboljšati vitalnost biljaka i povećati njihovu otpornost prema bolesti, što se posebno odnosi na urbane sredine. Drveće koje je inficirano ranijih godina treba prihraniti $u$ kasnu jesen ili u proleće, pre nego što se pupoljci otvore, a tokom sušnog vremena ga treba zalivati. Ova mera je vrlo važna zato što je potrebno da se održi što je moguće bolja kondicija inficiranih stabala, s obzirom da se bolest češće javlja i mnogo ozbiljnije posledice izaziva na stablima koja nisu vitalna.

Hemijske mere borbe ekonomski su opravdane u rasadnicima, jako zaraženim kulturama i urbanim sredinama. U jako zaraženim kulturama tretiranje treba vršiti svake treće ili četvrte godine, jer bi se posle prvog tretiranja nivo inokuluma znatno redukovao, tako da bi bilo potrebno nekoliko godina da dostigne isti nivo. Radi ekonomičnosti, prvu aplikaciju treba izvršiti u drugoj polovini aprila, a drugu u prvoj polovini maja. Tretiranje krajem aprila istovremeno bi bilo efikasno i protiv gljive Dothistroma septospora, koja predstavlja veliki i stalan problem u kulturama crnog bora. Zato se preporučuje korišćenje bakarnih fungicida, koji se teže spiraju i obezbeđuju dužu zaštitu (KARADŽIĆ, 1986; KARADŽıĆ I STOJADINOVIĆ, 1988).

U gradskim uslovima je, osim obaveznih uzgojnih i profilaktičkih mera, neophodno primeniti i hemijske mere borbe. S obzirom da su višegodišnja istraživanja pokazala da je gljiva $S$. sapinea u parkovima Beograda najopasniji parazit crnog bora, 1993. g. započeti su ogledi koji su trajali tri godine. Tretiranje je vršeno bakarnim fungicidom "Bacrocid S-50" u koncentraciji 0,7-1\% kome je dodato i folijarno đubrivo Wuxal. Zaštitom je obuhvaćeno 1500 stabala (na Kalemegdanu i Novom Beogradu), a kao kontrola je poslužilo 190 stabala. Znajući da je kritičan period za infekcije između sredine aprila i sredine maja, prva aplikacija bila je 15. aprila, a druga 5. maja. Pregled stabala, odnosno kontrola efikasnosti zaštite vršena je svake godine sredinom avgusta.

$\mathrm{Na}$ osnovu trogodišnjih ogleda, zaključeno je da se gljiva može efikasno suzbijati tretiranjem stabala bakarnim fungicidima, da su potrebne dve aplikacije $u$ vreme koje je kritično za infekcije, nakon čega je primena fungicida postala sastavni deo programa zaštite (KARADŽIĆ I SAR., 1993; 1995). 


\section{DISKUSIJA - Discusion}

Prema mnogobrojnim literaturnim izvorima iz raznih delova sveta, S. sapinea se najčešće navodi kao uzročnik uvenuća pupoljaka, krivljenja, zakržljalosti i nekroze izbojaka i četina iz tekuće vegetacije, sušenja grana sa vrha, izumiranja delova krune ili vrhova stabala (GIBSON, 1979; PETERSON, 1981a; SUTTON I DYKO, 1989; SWART I WINGFIELD, 1991a i mnogi drugi). S. sapinea može prouzrokovati i rak kore grana i debla što je konstatovano na Novom Zelandu, u Australiji i u SAD (CHOU, 1987; NiCHOLLS I OSTRY, 1990). Takođe sprečava klijanje semena Pinus vrsta, trulež u nivou korenovog vrata na mladim biljkama u rasadnicima i njihovo izumiranje (Neergaard, 1979). Kao uzročnik izumiranja korena borova konstatovana je u Južnoj Africi (SWART I WINGFIELD, 1991a) i u Kini (ZHONG I LIANG, 1990). Kao saprofit izaziva plavetnilo beljike sveže posečenog drveta (Neergaard, 1979), mada je obojenost drveta konstatovana i na dubećim stablima (GIBSON, 1979; PIOU I SAR., 1991). Ova gljiva može prouzrokovati i uvenuće krune, što je zabeleženo u mladim kulturama $P$. radiata na Novom Zelandu i Čileu (CHOU, 1987) i u Maroku, u kulturama $P$. halepensis i $P$. pinaster starosti između 6 i 10 godina (STIKI, 1994).

Ipak, glavni simptom i na mladim biljkama i na starijim stablima je izumiranje izbojaka iz tekuće vegetacije ("shoot blight"). Brojni istraživači širom sveta ovo potvrđuju: SINCLAIR I SAR. (1987), PALMER (1991), STANOSZ I SAR. (1995) u SAD; GIBSON (1979), SWART I WINGFIELD (1991a) u Africi; CHOU (1976a), (DAVISON I SAR.(1991) u Australiji i na Novom Zelandu; PIOU I SAR. (1991), DE KAM $(1985,1991)$, BUTIN (1989) u Evropi.

Prethodnim istraživanjima u Srbiji i Crnoj Gori, koja su se uglavnom odnosila na $P$. nigra i $P$. Halepensis, utvrđeno je da ova gljiva izaziva prvenstveno izumiranje izbojaka iz tekuće vegetacije, ali da može doći i do sušenja pojedinih gana u kruni ili vršnih delova stabala, odnosno do pojave suhovrhosti (KARADŽÍ́, 1983; KARADŽIĆ I STOJADINOVIĆ, 1988; KARADŽIĆ I VUJANOVIĆ, 1992; MILIJAŠEVIĆ, 2000). Međutim, u Srbiji i Crnoj Gori vrlo čest simptom je i nekroza i zakržljalost dvogodišnjih šišarica, ali i šišarica u prvoj godini razvoja. Ova istraživanja su to potvrdila.

Gljiva S. sapinea može ostvariti infekciju direktno kroz pupoljke, preko kore mladih izbojaka ili kroz stome mladih četina, mada su one moguće i preko ozleda na kori (Peterson, 1981a; CHOU, 1976a,1977; KARADžIĆ I StOJADINOVIĆ, 1988).

BROOKHOUSER I PETERSON (1971) su proučavajući infekcioni proces gljive na crnom, belom i ponderosa boru, vršili veštačke inokulacije pupoljaka desetogodišnjih stabala u polju, pri čemu su konstatovali da je inokulacija izazvala izumiranje pupoljaka. Ovo je ujedno i jedini podatak o sposobnosti gljive da inficira pupoljke koji je zasnovan na eksperimentu. Drugi istraživači na indirektan način govore o mogućnosti infekcije pupoljaka, najčešće opisujući simptome koje ove gljiva prouzrokuje. Naša istraživanja su pokazala da gljiva može ostvariti infekciju preko pupoljaka i prouzrokovati njihovo izumiranje. Takođe je utvrđeno da do infekcije može doći u proleće, pre otvaranja pupoljaka, ali i u leto, odnosno u godini njihovog formiranja, što predstavlja nov podatak u biologiji ove gljive. Izolacijom čiste kulture 
gljive iz pupoljaka crnog bora sakupljenih u zimskim mesecima, kao i konstatacijom piknida na njima, utvrđeno je da S. sapinea može i prezimiti u pupoljcima.

Do zaraze, ipak, najčešće dolazi preko mladih izbojaka i četina. Izbojci iz tekuće vegetacije su na infekciju gljive najosetljiviji u vremenskom periodu od dve nedelje posle otvaranja pupoljaka - od 20. aprila do 10. maja (PETERSON, 1981). CHOU (1976a, 1982b) je na Novom Zelandu utvrdio da je kritičan period infekcije od sredine do kasnog proleća (oktobar - novembar), u vreme otvaranja pupoljaka i porasta mladih izbojaka, mada su infekcije u prirodi zapravo moguće tokom cele godine. Ovakva vrsta istraživanja sprovedena u našoj zemlji potvrdila su prethodna.

Mogućnost infekcije muških cvetova na crnom, belom i ponderosa boru ispitivao je Peterson u SAD. S obzirom na činjenicu da je gljiva iz cvetova izolovana svega nekoliko puta, ovaj autor zaključuje da se infekcija ne može ostvariti preko cvetova, već pretpostavlja da se gljiva iz izbojaka širi i u cvetove. Rezultati naših istraživanja, koja su osim izolacije obuhvatila i identifikaciju piknida gljive na muškim i ženskim cvetovima, potvrdili su ovaj zaključak. Istraživanja su pokazala da je gljiva S. sapinea na crnom boru prisutna i na muškim i na ženskim cvetovima, kao i da na njima može obrazovati fruktifikacije. Činjenica da je gljiva izolovana samo iz cvetova sa zaraženih izbojaka, ukazuje na to da je infekcija najverovatnije ostvarena ili preko četina ili preko izbojaka, a da se zatim micelija proširila i u cvetove.

$S$. sapinea može inficirati i šišarice, pri čemu su posebno osetljive šišarice u drugoj godini razvoja na kojima se obrazuju brojni piknidi. Takođe, smatra se da na starijem drveću prvo dolazi do infekcije šišarica, a nakon toga izbojaka, čemu u prilog ide i činjenica da su jače zaraze konstatovane na stablima koja plodonose (PETERSON, 1981; KARADŽIĆ I STOJADINOVIĆ, 1988; PIOU I SAR., 1991). Na Deliblatskoj peščari ozbiljno su ugrožena stabla iznad 20 godina starosti (MARINKOVIĆ I KARADžıć, 1986; MILIJAŠEVIĆ, 1994b). Rezultati naših istraživanja pokazali su da su dvogodišnje šišarice crnog bora na infekciju osetljive u periodu od početka druge dekade aprila do kraja maja, kao i da do zaraze može doći i na šišaricama u prvoj godini razvoja. Izolacijom gljive iz jednogodišnjih šišarica crnog bora sakupljenih u zimskom periodu, utvrđeno je da ona u njima može prezimiti u vidu micelije.

Piknidi gljive se na zaraženim tkivima mogu naći tokom cele godine, ali se najčešće obrazuju sledeće godine nakon infekcije u osnovi izumrlih četina i na Šišaricama (MARINKOVIĆ I KARADŽIĆ, 1986; KARADŽIĆ I ANEELIĆ, 1997). BROOKHOUSER I PETERSON (1971) su, međutim, u istočnoj Nebraski konstatovali piknide sa nezrelim sporama na izbojcima i četinama najranije 13. juna, a sa zrelim sporama početkom avgusta. PETERSON (1977) je potvrdio da se plodonosna tela na četinama i šišaricama obrazuju u jesen iste godine, ukoliko je leto bilo jako kišno, ali ne pre proleća naredne godine ako su padavine bile ispod normale. Isti autor je nešto detaljnije ispitao obrazovanje piknida na dvogodišnjim šišaricama, pri čemu je došao do zaključka da na njihovo formiranje utiče količina padavina. Prema našim istraživanjima u prirodno inficiranim kulturama crnog i belog bora na Deliblatskoj peščari, piknidi gljive mogu se na izbojcima, četinama i dvogodišnjim šišaricama obrazovati u toku iste godine kada je ostvarena zaraza. Prve zrele fruktifikacije najčešće se formiraju u kori mladih izbojaka, u zoni infekcije i najranije su konstatovane u trećoj dekadi juna. $\mathrm{U}$ istom 
vegetacionom periodu kada je ostvarena infekcija konstatovana su plodonosna tela gljive sa zrelim konidijama i na jednogodišnjim i dvogodišnjim šišaricama.

Patogenost gljive ispitivali su brojni istraživači od početka prošlog veka. U Evropi i SAD ona je prema mnogim autorima patogena (DE KAM, 1991; PIOU I SAR., 1991; BUTIN, 1989; KARADŽIĆ, 1983; MARINKOVIĆ I KARADŽIĆ, 1986; BROOKHOUSER I Peterson, 1971; Peterson, 1981; Nichols I OstRy, 1990). SWART I WingField (1991) smatraju da se suprotni izveštaji po kojima su ozleđeno tkivo i stres potrebni da bi se infekcija ostvarila mogu objasniti postojanjem različitih sojeva gljive. Osim toga, klimatski faktori mogu odigrati značajnu ulogu u nastanku i razvoju bolesti. Oni na kraju, ipak, zaključuju da oštećenja od grada ili fiziološki stres nisu neophodni da bi došlo do zaraze i da je gljiva sposobna da u povoljnim klimatskim uslovima inficira neozleđene mlade izbojke. Na Novom Zelandu je CHOU (1976b) veštačkim inokulacijama $P$. radiata potvrdio sposobnost gljive da inficira neoštećene zelene izbojke.

Istraživanja u Srbiji potvrdila su da je $S$. sapinea patogen sposoban da inficira neozleđene mlade izbojke $P$. nigra, što je dokazano veštačkim infekcijama u kontrolisanim uslovima i u polju (KARADŽIĆ, 1989; MARINKOVIĆ I KARADŽÍć, 1986; MILIJAŠEVIĆ, 2000).

Morfološku varijabilnost konstatovali su mnogi istraživači koji su se bavili proučavanjem ove gljive. Utvrđene su razlike u veličini konidija i izgledu njihovog spoljnjeg zida, ali i u izgledu i brzini porasta kultura (CHOU, 1976b; SWART I WINGFIELD, 1991a,b; MORELET I CHANDELIER, 1993). Naša istraživanja pokazala su da je veličina konidija i na ovim prostorima varijabilna i da iznosi $14,8-51,4$ x 9,7 - 20,2 $\mu \mathrm{m}$. Utvrđeno je i to da na veličinu konidija utiču vrsta bora i biljni organ na kome se piknidi obrazuju.

Konidije gljive najbolje klijaju u temperaturnom intervalu između $20^{\circ}$ i $30^{\circ} \mathrm{C}$. Optimalna temperatura je $28^{\circ} \mathrm{C}$. Ovde treba ukazati i na veliku energiju klijanja, što je prema MARINKOVIĆU I KARADŽIĆU (1986) retko i što svakako igra značajnu ulogu u patogenezi.

Uticaj temperature na porast micelije gljive ispitivali su mnogi istraživači. Prema Brookhouser-U I Peterson-u (1971) ova gljiva je na podlozi PDA fiziološki aktivna u temperaturnom intervalu od $8{ }^{\circ} \mathrm{C}$ do $36{ }^{\circ} \mathrm{C}$, sa optimumom na $28{ }^{\circ} \mathrm{C}$ gde je prosečni dnevni porast iznosio $25 \mathrm{~mm}$. Prema PALMER I SAR. (1987), koji su ispitivali porast micelije sedam izolata gljive, optimalna temperatura za većinu izolata bila je 25 ${ }^{\circ} \mathrm{C}$. Prema SWART I SAR. (1991), optimalna temperatura za porast micelije gljive je 25 ${ }^{\circ} \mathrm{C}$. U Srbiji su KARADŽIĆ I MARINKOvIĆ (1986) utvrdili da micelija gljive raste u temperaturnom intervalu između $8^{\circ}$ i $36{ }^{\circ} \mathrm{C}$, sa optimumom na $28{ }^{\circ} \mathrm{C}$. Naša istraživanja su pokazala da je optimalna temperatura za porast micelije na podlogama PDA i MEA $28^{\circ} \mathrm{C}$, mada je vrlo sličan porast i na $25^{\circ} \mathrm{C}$.

Detaljnija ispitivanja uticaja svetla i sterilnih četina na sporulaciju gljive vršili su PALMER I SAR.(1987). U njihovim istraživanjima korišćeno je 7 izolata, iz P. nigra, P. resinosa, P. mugo i P. banksiana, poreklom iz SAD. Kulture su rasle na PDA u mraku ili pri stalnom veštačkom svetlu na temperaturi $25^{\circ} \mathrm{C}$, sa ili bez sterilnih četina $P$. resinosa, koje su stavljene na površinu podloge. Posle šest dana svi izolati koji su 
se razvijali na svetlu, obrazovali su konidije na sterilnim četinama ili na miceliji. Formiranje piknida bilo je kod svih izolata mnogo obilnije na četinama nego na miceliji. Naša istraživanja su pokazala da na sporulaciju utiču svetlost i prisustvo sterilisanih četina na miceliji. Posle 14 dana izlaganja dnevnom svetlu obrazovali su se piknidi, kod većine sa zrelim konidijama, dok su se posle istog perioda inkubacije u mraku samo kod tri izolata obrazovale zrele piknospore. Fruktifikacije gljive se uvek brže i u većem broju formiraju na četinama nego na miceliji.

S obzirom na veliki značaj ove gljive i na štete koje izaziva u mnogim zemljama širom sveta, o mogućnosti njenog suzbijanja postoje brojni literaturni podaci, a prema većini autora uzgojne i profilaktičke mere predstavljaju najbolji ili ponekad i jedini mogući način kontrole ovog patogena. Preventivne mere koje se koriste u suzbijanju gljive $S$. sapinea zasnivaju se na smanjenju nivoa inokuluma i mogu se primeniti u rasadnicima, kulturama, vetrobranim pojasevima i u urbanim sredinama. To je uklanjanje obolelih biljaka i biljnog materijala posle prorede kultura i orezivanja stabala. U SAD postoji program zaštite fungicidima koji je još davne 1939.g. dala WATERMAN (cit. Peterson I WYSONG, 1968). Ona je preporučila uklanjanje i uništavanje obolelih izbojaka u jesen i prskanje Bordovskom čorbom $u$ proleće. Za uspešno suzbijanje gljive potrebne su tri aplikacije: prva u vreme kada novi izbojci počinju da rastu, druga kada se četine pojavljuju iz rukavaca i treća kada su četine delimično porasle. Preporučuje se i četvrta aplikacija, ukoliko je vreme posebno pogodno za infekciju ili ukoliko je razvoj novih izbojaka nešto sporiji. PETERSON (1981) je utvrdio da će se infekcija jednogodišnjih izbojaka značajno smanjiti upotrebom fungicida $u$ toku dve nedelje kada su izbojci najosetljiviji (krajem aprila-početkom maja). U ovom periodu potrebno je izvršiti dva tretiranja Bordovskom čorbom.

Naša istraživanja su pokazala da je u gradskim uslovima, osim obaveznih uzgojnih i profilaktičkih mera, neophodno primeniti i hemijske mere borbe. $\mathrm{Na}$ osnovu trogodišnjih ogleda zaključeno je da se gljiva može efikasno suzbijati tretiranjem stabala bakarnim fungicidima $i$ da su potrebne dve aplikacije u kritičnom periodu za infekcije.

\section{ZAKLJUČCI - Conclusions}

- Sphaeropsis sapinea je široko rasprostranjena u Srbiji i Crnoj Gori, i u kontinentalnom i u mediteranskom delu. Konstatovana je na deset vrsta borova i na pet domaćina iz drugih četinarskih rodova. $P$. peuce i $P$. heldreichii su nove biljke domaćine gljive na ovim prostorima.

- Najosetljivije su Pinus vrste, dok se na vrstama iz drugih četinarskih rodova javlja sporadično i ne izaziva veće štete.

- Glavni simptomi su uvenuće pupoljaka, zakržljalost i nekroza izbojaka i četina iz tekuće vegetacije, nekroza, deformacija i zakržljalost šišarica u prvoj i drugoj godini razvoja.

- S. sapinea može ostvariti infekciju preko pupoljaka i prouzrokovati njihovo izumiranje. Do zaraze može doći pre otvaranja pupoljaka u proleće, ali i u godini 
njihovog formiranja. U pupoljcima gljiva može prezimiti, bilo u vidu micelije, bilo u vidu piknida.

- Kritično vreme infekcije predstavlja period od sredine aprila do sredine maja kada se infekcije ostvaruju preko mladih izbojaka.

- Dvogodišnje i jednogodišnje šišarice su takođe podložne infekciji; u jednogodišnjim šišaricama gljiva i prezimljava u vidu micelije.

- Piknidi sa zrelim konidijama mogu se obrazovati na izbojcima, četinama, jednogodišnjim i dvogodišnjim šišaricama u toku iste godine kada je ostvarena zaraza.

- Ispitivanjem patogenosti gljive utvrđeno je da je ovaj parazit sposoban da inficira neozleđene mlade izbojke $P$. nigra.

- Optimalna temperatura za klijanje spora i porast inicijalne hife je $27{ }^{\circ} \mathrm{C}$, za porast micelije na podlogama krompir-dekstroza agar i malc-ekstrakt agar je $28^{\circ} \mathrm{C}$.

- Analiza obrazovanja plodonosnih tela u kulturi pokazala je da na sporulaciju utiču svetlost i prisustvo sterilisanih četina na miceliji.

- Pravilne i blagovremene mere suzbijanja mogu doprineti da se posledice ove ozbiljne bolesti umanje, kombinovanom primenom uzgojnih i hemijskih mera borbe. Gljiva se može efikasno suzbijati tretiranjem stabala bakarnim fungicidima, a za uspešnu zaštitu biljaka potrebne su dve aplikacije u vreme koje je kritično za infekcije.

\section{LITETERATURA - References}

Bоотн, C. (1971): Methods in Mycrobiology, Vol.4. Academic press, London and New York

Brookhouser, L.W.; Peterson, G.W.(1971): Infection of Austrian, Scots, and Ponderosa Pines by Diplodia pinea. Phytopathology, 61 (4): 409 - 414.

Butin, H. (1989): Krankheiten der Wald - und Parkbäume. Diagnose - Biologie Bekämpfung. Georg Thieme Verlag Stuttgart - New York

CHOU, C.K.S. (1976a): A Shoot Dieback in Pinus radiata caused by Diplodia pinea. 1. Symptoms, Disease Development, and Isolation of Pathogen. New Zealand Journal of Forestry Science, 6 (1): 72 - 79.

CHOU, C.K.S. (1976b): A Shoot Dieback in Pinus radiata Caused by Diplodia pinea. II. Inoculation Studies. New Zealand Journal of Forestry Science 6 (3):409 - 420.

CHOU, C.K.S. (1977): Effect of Tree Age on Diplodia pinea Infection of Pinus radiata Plant Disease Reporter 61(2):101 - 103.

CHou, C.K.S. (1978): Penetration of young stems of Pinus radiata by Diplodia pinea. Physiological Plant Pathology, 12: 189 - 192.

CHOU, C.K.S. (1981): Suppression of Diplodia pinea Spore Germination at the Shoot Surface of Pinus radiata. New Zealand Journal of Forestry Science 11 (1): 3 - 7.

CHOU, C.K.S. (1982a): Diplodia pinea infection of Pinus radiata seedlings: Effect of Temperature and Shoot Wetness Duration. New Zealand Journal of Forestry Science $12(3): 425-437$. 
CHOU, C.K.S. (1982b): Susceptibility of Pinus radiata Seedlings to Infection by Diplodia pinea as Affected by Pre-Inoculation Conditions. New Zealand Journal of Forestry Science $12(3): 438$ - 441.

CHOU, C.K.S. (1987): Crown wilt of Pinus radiata associated with Diplodia pinea infection of woody stems. Eur. J. For. Path. 17 (1987) 398 - 411.

Davison, E.M.; TAY, F.C.S.; PeronI, D. (1991): Sphaeropsis sapinea on pines in Western Australia. Rev. of Plant Pathology, 70 (9):761 (abstr.).

DE KAM, M. (1985): Sphaeropsis (=Diplodia) shoot-dying: an incident or a permanent problem?. Nederlands Bosbouqtijdschrift 57 (4):118 - 122.

DE KAM, M. (1991): Sphaeropsis sapinea in Nederland. Nederlands Bosbouw Tijdschrift $160-167$.

Gerhold, H.D.; Rhodes, H.L.H.; WenneR, N.G. (1994): Screening Pinus sylvestris for Resistance to Sphaeropsis sapinea. Silvae Genetica 43, 5/6, 333 - 338.

GIBSON, I.A.S. (1979): Diseases of Forest Trees Widely Planted as Exotics in the Tropics and Southern Hemisphere. Part II. The genus Pinus. Commonwealth Mycological Institute, Kew; 135 p.

LULEY, C.J.; GleAson, M.L. (1988): Diplodia Canker (Sphaeropsis sapinea) of Abies concolor in Iowa. Plant Disease 72:79.

KARADŽIĆ, D. (1983): Bolesti četina crnog bora (Pinus nigra Arn.). Zaštita bilja, 34 (3), 165: 329 - 342, Beograd.

KARADŽlć, D. (1986): Proučavanje bioekologije gljive Dothistroma pini Hulbary prouzrokovača osipanja četina crnog bora. Doktorska disertacija, Šumarski fakultet, Beograd.

KARADŽÍc, D.; StOJADINović, B. (1988): Prilog poznavanju gljive Sphaeropsis sapinea Dyko et Sutton sa posebnim osvrtom na životni ciklus. Šumarstvo br.5 - 6, str. 17 - 27.

KARADŽıć, D. (1989): Mehanizam infekcije nekih gljiva na četinama crnog i belog bora. Zaštita bilja, 40 (1), 187: 35 - 46, Beograd.

KARADŽIĆ, D.; VUJANOVIĆ,V. (1992): Prilog poznavanju patogene mikoflore bora (Pinus halepensis Mil.) u mediteranskom delu Crne Gore. Glasnik Šumarskog fakulteta, 74: $31-41$.

KARADŽIĆ, D.; ANĐELIĆ, M. (1997): Uticaj patogene mikoflore na sušenje stabala alepskog bora (Pinus halepensis M ill.) u kulturama u okolini Skadarskog jezera. Zbornik radova "Prirodne vrijednosti i zaštita Skadarskog jezera". Naučni skupovi, knjiga 44, str.291-298. Podgorica, 1997.

KARADŽIĆ, D.; MILIJAŠEVIĆ, T. (1998): The effect of pathogenic mycoflora on the destruction and dieback of trees in Pinus plantations in Serbia. Proceedings scientific Papers. Jubilee Scientific Conference with International Participation "70-th Anniversary of the Forest Research Institute", 6-7. October 1998, Sofia, str. 233-239.

KaradžIĆ, D.; Zarubica, B.; Radovanović, S.; MiliJašEvić, T. (1993): Sphaeropsis sapinea - biologija, značaj i suzbijanje na zelenim površinama Beograda. Prvo 
jugoslovensko savetovanje o zaštiti bilja, V.Banja, 30.11 - 3.12.1993. Zbornik rezimea, str. 79.

KARADŽIĆ, D.; ZARUBICA, B.; MILIJAŠEVIĆ, T. (1995): Mogućnosti suzbijanja patogene gljive Sphaeropsis sapinea Fr.) Dyko a Sutton u parkovima Beograda. Biljni lekar br. 6, str. $612-615$.

MARINKOVIĆ, P.; KARADŽIĆ, D. (1986): Izumiranje četina i izbojaka - Sphaeropsis sapinea (Fr.) Dyko a. Sutton - novo opasno oboljenje crnog bora. Deliblatski pesak Zbornik radova $\mathrm{V}$, str. $29-38$.

MILIJAŠEVIĆ,T. (1987): Proučavanje biologije gljive Cytospora friesii Sacc. na četinama Abies concolor. Magistarski rad, odbranjen 9.1.1987. na Šumarskom fakultetu u Beogradu.

MILIJAŠEVIĆ, T. (1994a): Sphaeropsis sapinea (Fr.) Dyko a Sutton - patogen Pinus vrsta u Jugoslaviji. Monografija "Zaštita bilja danas i sutra" - editori: Šestović, M.; Nešković, K.N.; Perić, I., str. 637-652, Beograd.

MILIJAŠEVIĆ, T. (1994b): Neka nova proučavanja patogene gljive Sphaeropsis sapinea (Fr.) Dyko a Sutton u kulturama crnog i belog bora na Deliblatskoj peščari. Deliblatski pesak - Zbornik radova VI, 1994, str. 521 - 528, Pančevo.

MILIJAŠEVIĆ,T. (1994c): Sphaeropsis Blight in Yugoslavia. Shoot and Foliage Diseases in Forest Trees, p.273 (abstr.). Proceeding of a Joint Meeting of the Working Parties Canker and Shoot Blight of Conifers, Vallombrosa, Firenze, Italy June 6-11, 1994.

MILIJAŠEVIĆ, T. (2000): Proučavanje bioekologije gljive Sphaeropsis sapinea Dyko \& Sutton - prouzrokovača propadanja Pinus vrsta u urbanim sredinama i prirodnim rezervatima. Doktorska disertacija, odbranjena 28.7.2000.g. na Šumarskom fakultetu u Beogradu.

Morelet, M.; ChAndelier, P. (1993): A Case of Variability in Sphaeropsis sapinea. Eur. Jour. of For. Path. 23:5, 317 - 320.

NeergaARd, P. (1979): Seed Pathology. The Macmillan Press Ltd. Volume I.

Nicholls, T.H.; OstRY, M.E. (1990): Sphaeropsis sapinea Cankers on Stressed Red and Jack Pines in Minnesota and Wisconsin. Plant Disease, vol. 74, No. 1, 54 - 56.

Palmer, M.A.; SteWART, E.L.; Wingfield, M.J. (1987): Variation Among Isolates of Sphaeropsis sapinea in the North Central United States. Phytopathology, 77 (6): 944 -948

PALmer, M.A. (1991): Isolate types of Sphaeropsis sapinea Associated with Main Stem Cankers and Top-Kill of Pinus resinosa in Minnesota and Wisconsin. Plant Disease, Vol.75, No.5, 507 - 510.

Peterson, G.W. (1977): Infection, Epidemiology, and Control of Diplodia Blight of Austrian, Ponderosa, and Scots Pines. Phytopathology 67: 511 - 514.

Peterson, G.W. (1981): Diplodia Blight of Pines. U.S. Department of Agriculture, Forest Service, Forest Insect and Disease Leaflet 161, 7 p. Washington, D.C.

Peterson, G.W.; WYsong, D.S. (1968): Diplodia Tip Blight in the Central Great Plains: Damage and Control. Plant Disease Reporter, 52 (5):359 - 360. 
Piou, D.; Chandelier, M.; Morelet, M. (1991): Sphaeropsis sapinea un nouveau probleme sanitaire des pins en France?. Rev.For.Fr. XLIII - 3, 203 - 213.

SHEN, B.K. (1990): Pine die-back disease found in Jiangsu Province. Rev. of Plant Path.70 (1):65 (abstr.).

SinClAIR, A.W.; LyON, H.H.; Johnson, T.W. (1987): Diseases of Trees and Shrubs. Cornell University Press, Ithaca and London.

Stanosz, G.R.; Trobaugh, J.; Prey,A. (1995): Paper Mill Waste, Red Pine Nutrition, and Sphaeropsis Shoot Blight and canker Disease in Wisconsin, USA. IUFROmXX World Congress, 6 - 12 August 1995, Tampere, Finland.

STIKI, A. (1994): Crown Wilt of Pinus Associated to Sphaeropsis sapinea Infection of Woody Stems. Shoot and Foliage Diseases in Forest Trees, p. 271-272. Proceeding of a Joint Meeting of the Working Parties Canker and Shoot Blight of Conifers and Foliage Diseases, Vallombrosa, Firenze, Italy June 6 - 11, 1994.

SUTTON, B.C.; DYKO, B.J. (1989): Revision of Hendersonula .Mycol. Res. 93 (4): 466 - 488.

SWART, W.J.; Wingfield, M.J. (1991a): Biology and Control of Sphaeropsis sapinea on Pinus Species in South Africa. Plant Disease, Vol.75, No.8, 761 - 766.

SWART, W.J.; WINGFIELD, M.J. (1991b): Conidial morphology of Sphaeropsis sapinea. Phytopathology, 81((10):1235.

SWART,W.J.; Wingfield, M.J.; KNOX-DAVIES,P.S. (1988): Relative susceptibilities to Sphaeropsis sapinea of six Pinus spp. cultivated in South Africa. Eur. J. For. Path. 18 (1988) 184 - 189.

Swart, W.J.; Wingfield, M.J.; Palmer, M.A.; Blanchette, R.A. (1991): Variation Among South African Isolates of Sphaeropsis sapinea. Phytopathology, Vol. 81, No.5, $489-493$.

ZHONG, X.P.; LIANG, Z.C. (1990): Diplodia and Botryodiplodia root rot of pines. Rev. of Plant Path.70 (7): 569. (abstr.).

\section{SUMMARY - Sažetak}

S. sapinea is a cosmopolitian and polyphagous pathogenic fungus, identified in more than 50 countries of the world. The greatest damages have been occured on Pinus species. In Serbia and Montenegro it is widely distributed both in the continental and Mediteranean part. It is recorded on ten Pinus species $-P$. nigra, P. sylvestris, $P$. halepensis, $P$. pinaster, $P$. jeffrey, $P$. ponderosa, $P$. pinea, $P$. heldreichii, $P$. peuce, $P$. mugo, and on species of six other coniferous genera - Abies concolor, Cedrus atlantica, Chamaecyparis lawsoniana, Cupressus sempervirens, Juniperus virginiana and Thuja occidentalis. Most of the damages occured in Austrian and Allepo pine plantations and also in urban areas. For the first time $S$. sapinea was registered in Serbia on Pinus nigra in 1981. On $P$. heldreichii, a Tertiary relic and a Balkan subendemic, it was first recorded on individual trees near Pećka Patrijaršija in 1993, and after that, near the Monastery Ostrog. It was the first report of $S$. sapinea on this plant host in Serbia and 
Montenegro. S. sapinea can infect almost each part of host plant, causing many symptoms. However, the most common symptoms are shoot blight, characterized by stunted dead shoots and needles, bud wilt, stem cankers and branch dieback. It also causes the necroses of the seed cones and their dwarfishness. S. sapinea penetrates through buds, bark of young shoots and needles. The critical period of infection is from middle of April till the middle of May, when infections mainly occur through the bark of young shoots, which results in their dying. The very early symptoms on the young shoots were mostly observed at the first part of May. Changing of color of infected needles can be seen at the beginning of June, while in the middle of June they become yellow-brown. Infections through the needles occur mainly at the time of their sudden growth or during summer months. Second year seed cones are susceptible to the infection in the second decade of April. Current year seed cones can be infected as well. Pycnidia have been observed on young shoots and needles, pollen and seed cones, buds, current year and second year cones, and in the bark of older branches $P$. nigra. Pycnidia with mature conidia can be formed during the same year of infection. In the bark of young shoots, they were identified at the end of June and on the cones at the beginning of the third decade of July. The size of $S$. sapinea conidia on different Pinus species is very variable throughout the world and ranges widely from 16.8-55.0 $\mathrm{x} 7.0-21.0 \mu \mathrm{m}$. Our study shows that the size of pycnospores in our country is also variable and it ranges $14.8-51.4 \times 9.7-20.2 \mu \mathrm{m}$. S. sapinea is parasite able to infect undamaged young shoots of $P$. nigra. It is proved by artificial inoculations in controlled conditions and in the field. The optimal temperature for spore germination and germ tube growth is $27^{\circ} \mathrm{C}$, and the optimal temperature for mycelia growth on the media PDA and MEA is $28{ }^{\circ} \mathrm{C}$. The formation of fruiting bodies in the culture is affected by light and the presence of sterilised needles on the mycelium. The correct and timely control measures can contribute to reduce the consequences of this serious disease, by the combined application of silvicultural and chemical measures. Chemical control is recommended in the nurseries, severely infected plantations and in urban environments. The copper fungicides showed the greatest efficiency. 